\title{
Knowledge and practices on maternal health care among mothers: A case study from Sewar Bansbot village of Dang district
}

\author{
Ganga $\mathrm{KC}, \mathrm{PhD}{ }^{*}$
}

\begin{abstract}
Knowledge and practices regarding maternal health care among women has had a significant shift in Nepali culture. Understanding this ship can help to improve women's overall status. Nepal implemented a safe motherhood program, which slightly improved maternal health. Data, showed the maternal mortality ratio decreased during the period between 1996 and 2016 but still there is high ratio in maternal mortality. Conservative practices of maternal health are prevalent to this date. Health education is one of the crucial factors empowering women to be attentive of their rights and health status to get appropriate health services. Maternal health is a major burning issue in Nepal, which has been affected mainly due to early marriage, teenage pregnancy, superstition, low women literacy rate, and unhygienic behavioural practices. Women go through a rather depressing situation due to workload ignorance, lack of health facilities, economic, and social conditions. Despite the efforts from various types of private, government, and voluntary health agencies, there has not been a satisfactory improvement in maternal health status and safe motherhood. This study focuses on theknowledge and practices of maternal Health care. It also describes antenatal care, delivery care, and postnatal care. The study was conducted in Sewar Basbot village of ward no. 13, Ghorahi Sub-metropolitan city of Dang district that is situated near by district headquarters, Ghorahi. In total, 45 women of reproductive age (15-49 years) who were pregnant and having children below five years of age were purposively interviewed and completed the self-administered interview schedule.
\end{abstract}

Key Words: Attitude, knowledge, maternal health care, prenatal, postnatal care practice.

\section{Introduction to Maternal Health}

Maternal health refers to the physical, mental, social and psychological health condition of mothersduring pregnancy. Childbirth, and the postnatal period is one of the

${ }^{*}$ Dr. KC has been working as the Associate Professor at the Department of Anthropology, Patan Multiple Campus, Tribhuvan University, Nepal. 
critical issues on reproductive health. Maternal health is closely related to safe motherhood ensuring women and their babies reach their full potential for health and well-being. Socio-economic factors are directly associated with knowledge and practices on maternal health such as taboos related to the pregnancy period, belief on childbearing, dietary practice, obstructive problem, health facilities etc. It should be addressed to reduce maternal mortality, infant mortality, as well as child mortality. Maternal mortality in developing countries compared to developed countries is considerably high. The most common direct cause of maternal injury and death are excessive blood loss, infection, high blood pressure, unsafe abortion, and obstructed labor, and indirect causes such as anemia, malaria, and heart disease. Most maternal deaths can be prevented through suitable management by a skilled health professionals working in a supportive environment. It is critical to magnify efforts to reduce maternal injury and disability and to promote health and security. Every pregnancy and birth is unique. Addressing disparities that affect health outcomes, especially sexual and reproductive health, and rights, and gender is fundamental to ensure all women access to respectful and high-quality maternity care.

Maternal mortality is excessively high. About 295,000 women died during and following pregnancy and childbirth in 2017. The vast majority of these deaths (94\%) happened in low-resource settings, and most could have been prevented (WHO, 2019). So this issue has been important in the discipline of medical anthropology. This study deals with the anthropological aspects of the maternal health, ethnic and indigenous practices of maternal health, cultural practices of different caste and ethnic groups. It discusses the various aspects of maternal health which are directly related with the issue like antenatal and postnatal practices.

According to WHO (2015) most maternal deaths are preventable and health-care solutions to prevent or manage complications are well known. Proper care in pregnancy, and during and after delivery should be accessible to all women. Maternal health and newborn health car ear closely linked. It is important that trained health specialists attend all births, as suitable management and treatment can outstand the risks associated to life and death for the motherland the baby.

The latest available data suggests that in the highest income and upper-middleincome countries, more than $90 \%$ of all births benefit from the presence of a trained midwife, doctor, or nurse (WHO, 2015). In contrast, such skilled health personnel assist fewer than half of all births in several low incomes and lower-middle-income countries (WHO, 2019). WHO (2019) further recognized that poverty, distance to facilities, lack of information, inadequate and low quality services, cultural beliefs and practices have been identified as the main factors that prevent women from receiving or seeking care during pregnancy. 
WHO (2013) reported that in 2012, approximately 213 million pregnancies occurred worldwide. During the pregnancy some of the pregnant women will experience some types of complication. Because of this complication, some of the mothers die each year from causes related to pregnancy, most of which could be prevented. The maternal mortality ratio (MMR) in Nepal decreased from 539 maternal deaths per 100,000 live births to 239 maternal deaths per 100,000 live births between 1996 and 2016. In 2016, roughly $12 \%$ of deaths among women of reproductive age were classified as maternal deaths (MoHP, 2016). This paper has great importance to investigate and describe women's knowledge and practices on maternal health.

\section{Maternal Health Care Practice in Nepal}

Pregnancy and childbirth is a normal physiological phenomenon, and almost every woman goes through this process of pregnancy and childbirth at least once in her lifetime. However, there are many adversities like abortion, maternal or fetal disability, and even maternal death or fetal loss or both that lead to termination of pregnancy or pregnancy termination (Gupta and Paul, 2005). Each pregnancy is considered at risk and associated with complications during pregnancy, childbirth, and the postnatal period. But, it is difficult to predict them (DoHS, 2011). Maternal mortality and disability are remarkably high in Nepal as pregnancy and childbirth are not taken change as major events in one's life that demand proper devotion and efforts rather, they are perceived as biological phenomena only (WHO, 2006).

In Nepal, pregnancy and delivery are viewed as a natural process, requiring no health care intervention. Childbearing women and their families only seek care when the condition becomes life-threatening. Traditionally, childbirth takes place in a cowshed, and local materials are used for delivery and cord care. Strong religious and cultural belief and practices regarding reproduction is deeply embedded in the traditional societies of Nepal (Levitte et al. 1998). But recently, the scenario has been changed in the context of Nepal. According to MoHP (2017), there were 239 maternal deaths reported per 100,000 live births which also states that between 2011 and 2016, there was a $22 \%$ increase in both the proportion of institutional deliveries (from $35 \%$ to $57 \%$ ) and births assisted by SBAs (skilled birth attendance) (from 36\% to 58\%).Doctors administered $31 \%$ of total deliveries, and nurses and midwives/auxiliary nurse midwives helped $27 \%$. While the percentage of deliveries attended by traditional birth attendants decreased from $11 \%$ in 2011 to $5 \%$ in 2016, the home birth rate remained high at $41 \%$ (MoHP, 2017).

One of the goals of Millennium Development Goals (MDG) is to improve maternal health, and the government of Nepal has committed to achieving these goals by addressing barriers. To address these issues, the minimum package of essential safe- 
motherhood services was developed in Nepal, and services under the package box include supplementation of iron and folic tablets, counseling about nutrition, rest, recognition of danger signs, and preparedness/readiness for service consultation and motherhood during pregnancy, the arrangement of place for delivery, and clean/safe delivery practices and postnatal care practices (WHO, 2013). Despite these efforts, ANC practices in the Midwestern development region of Nepal is relatively low, and the dropout rate (first ANC vs. fourth ANC visit) is very high (50.0\%, four ANC visits), and only $50 \%$ of the expectant mothers had one postnatal visit which is the lowest achievements in the national statistics (MoHP, 2017). As a matter of fact, lack of proper knowledge among the pregnant mothers and her relatives, poor access, and acceptance of maternity services, including delay in seeking and receiving care, are some of the recognized obstacles in Nepal. To address the issue, the government of Nepal has adopted promotional strategies for awareness, readiness, and preparedness on the complication of pregnancy and extension of obstetric services in the country. Therefore, promotion of health and reduction of adverse pregnancy outcomes requires the entire range of care starting right from conception up to the postpartum period. In this context, the study was carried out to assess the mother's maternal healthcare knowledge and to identify the respondents' practices in terms of antenatal care, delivery care, and postnatal care.

Because of the early marriage, teenage pregnancy, superstition, low women literacy rate, unhygienic health behavioural practices, maternal and child health status has not improved, and most of the local women do not utilize health services properly, not aware of the available health services in their locality. Women are facing this very depressing situation due to workload ignorance, lack of health facilities, economic and social conditions. Despite, various programs for improving the maternal health status and to assure safe motherhood have been launched by private, government, voluntary health agencies, there isstillno satisfactory result found. Maternal health care has three major concepts- prenatal, delivery and postpartum healthcare practices for the mothers. In other words these practices can be described as pregnancy care of before birth, delivery and after birth practices which include treatments and training to ensure a healthy pregnancy, labor and delivery for mother and baby.According to MoHP (2017), the goal of the National Safe Motherhood Program is to reduce maternal and neonatal morbidity and mortality and to improve maternal and neonatal health through preventive and promotive activities as well as by addressing avoidable factors that cause death during pregnancy, childbirth, and the postpartum period.

The Government of Nepal introduced demand-side intervention in maternal health to improve institutional delivery. The Maternity Incentive Scheme was the first such intervention, launched in 2005 and designed to share the cost of transportation to 
the health facilities. In 2009, transport incentive; user fees were removed from all types of delivery care, known as the Aama Program. In 2012, a separate demand-side intervention called 4 ANC incentives program (introduced in 2009) has been merged with Aama Program. In Fiscal Year (FY) 2073/74, the free newborn care program (introduced in FY 2072/73) has been merged into the Aama program. Aama program in its current form is known as the Aama and Newborn program and has the following provisions. (MoHP, 2017).

The safe motherhood program is one of the effective programs of Nepal. The primary objectives of National Health Policy (1991) were to reduce maternal and neonatal mortality and morbidity. The safe motherhood approaches have been adopted for improving maternal health in a holistically improving maternal health way. The primary intervention for reducing maternal mortality is universal access to assistance at birth by a skilled birth attendant and provision of essential and emergency obstetric care. This is further supported by access to family planning and management of unwanted pregnancies. This study was concentrated on the description of knowledge and practices on maternal health care.

For the safe motherhood, the Government of Nepal implemented the 'Sunaula 1000 Din Program' (golden 1000 days Program). It was the community's actions for nutrition projects for pregnant women and delivered mothers. This program was implemented from October 2012 to March 2017. In Nepali, "SunaulaHazar Din" means, "Golden 1000 Days", which is a critical window of opportunity between conception and the age of two years that, with good health and nutrition, can mitigate the risks of malnutrition that hamper a child's long-term physical and cognitive development (Oshima \& Bhattarai, 2017). Similarly, others like Gyawali et.al (2013), Low et. al (2016) have also attempted to researched in this topic. But these are limited to medical field and not applying the concept of anthropology.

\section{Objective and research methods}

The prime objective of this paper is to find out knowledge and practice on maternal health care among mothers. More specifically, this study attempts to deal withantenatal care, delivery care, and postnatal care practices of maternal health care. The fieldwork was carried out in 2019, in Sewar Basbot village, ward no.13 of Ghorahi sub-metropolitan of Dang district. This area was purposively selected for the study. For the data collection, the interview schedule, and key informant interview method were adopted. The target group was45 women of reproductive age (15-49 years) having children below five years selected by using purposive sampling. Both qualitative and quantitative data are used in this study. Primary data were gathered through the use of 
key informant interviews likewise, secondary data were collected from published sources, documents, and websites.

\section{Discussion on findings}

\section{Socio-demographic profile of the respondents}

The socio-economic characteristics of the mothers significantly influenced maternal health-care services. A significant difference was observed among mothers with different occupations. The mean age of the respondents was 27 years. The majority of the respondents were Tharu 27 individuals followed by Kshetri 7 individuals, Brahmin 3 individuals, Magar 5 individuals, and the Blacksmith 3 individuals. Most of the respondents (29) were living in a nuclear family, and only 16 respondents were living in a joint family. Among the 45 respondents, 24 were labor by occupation followed by housewife 14, agriculture 5 and government service 2. Likewise, 35 respondents were Hindu, 5 were Christian and Buddhist were 5 by religion, as shown in table no.1.

Table 1: Socio-demographic profile of the respondents

\begin{tabular}{|l|l|l|}
\hline Characteristics & Number & Percentage \\
\hline Age groups & & \\
$15-20$ & 5 & 11.1 \\
$21-27$ & 25 & 55.6 \\
$28-34$ & 9 & 20.0 \\
$35-41$ & 4 & 8.9 \\
$42-49$ & 2 & 4.5 \\
\hline Total & 45 & 100.0 \\
\hline Caste and ethnicity & & \\
Kshetri & 7 & 15.5 \\
Brahman & 3 & 6.7 \\
Tharu & 27 & 60.0 \\
Magar & 5 & 11.1 \\
Blacksmith & 3 & 6.7 \\
\hline Total & 45 & 100.0 \\
\hline Family structure & & 35.5 \\
Joint & 16 & 64.5 \\
Nuclear & 29 & \\
\hline Total & 45 & 100.0 \\
\hline
\end{tabular}




\begin{tabular}{|l|l|l|}
\hline Educational level & 9 & 20 \\
Illiterate & 8 & 17.7 \\
Literate & 18 & 40.0 \\
Primary & 7 & 15.6 \\
Secondary & 3 & 6.7 \\
Bachelor & 45 & 100.0 \\
\hline Total & & \\
\hline Occupation & 5 & 11.1 \\
Agriculture & 2 & 4.5 \\
Govt. service & 24 & 53.3 \\
Labour & 14 & 31.1 \\
Housewife & 45 & 100.0 \\
\hline Total & & \\
\hline Religion & 35 & 77.8 \\
Hindu & 5 & 11.1 \\
Christian & 5 & 11.1 \\
Buddhist & 45 & 100.0 \\
\hline Total & & \\
\hline Sourc: & & \\
\hline
\end{tabular}

Source: Field study, 2019.

Education was found to have the most powerful influence on the knowledge score of maternal health. Knowledge not only transforms but also empowers women and improves their self-esteem (Renkert \& Nutbeam, 2001). It is expected that educated women are more likely to be conscious of their health status and seek health-related information. Furthermore, educated women may have more enormous decision-making power on Health-related matters. Different studies and national report shows that a large number of rural women in Nepal, at present, have minimal education, and to access maternal Health education is a challenging task for them. This reality was substantially valid in the study area too. According to table 1 the educational level of the respondents was not sound. Among the 45 respondents, only 3 respondents had bachelor level education, followed by 18 respondents with primary education, and 9 respondents were illiterate. 8 respondents were literate, followed by 7 respondents with secondary education.

Cultural factors such as ethnicity and religious beliefs have been stated through various studies carried out indifferent parts of the world to influence the use of maternal health services and need to be taken into account for any successful interventions (WHO, 2005, 2007). Similarly, the government of Nepal has applying different 
approaches that address the ethno-religious barriers to facilitate the optimum utilization of ANC, natal and postnatal maternal health services.

\section{Knowledge of Maternal health care}

Health education is considered as one of the key factors that empower women to be attentive of their right to good health and to getsuitable health facilities. Maternal Health refers to the health status of women during pregnancy, childbirth, and the postnatal period. These periods are valuable and full of high risks for mothers. Sound knowledge of maternal health care is must for mothers. Table 2 shows the respondent's knowledge of pregnancy-related health conditions and symptoms that pose risk to the mother. Vomiting, headache, and acidity were the most mentioned pregnancy- related conditions, followed by irregular movement of the foetus. The swelling of hands, legs, and face was the least known among women in this study. Lower abdominal pain during the pregnancy period was not mentioned by the respondents.

Table 2: Respondents knowledge ofpregnancy-related conditions

\begin{tabular}{|l|l|l|}
\hline Description & Number & Percentage \\
\hline Knowledge of the frequency of minimum visits of ANC & & \\
Yes & 25 & 55.5 \\
No & 20 & 44.5 \\
\hline Knowledge of WHO guideline for ANC for pregnancy & & \\
checking & 14 & 31.1 \\
Yes & 31 & 68.9 \\
No & & \\
\hline Knowledge of risky symptoms during pregnancy & 34 & 75.5 \\
Vomiting, headache, and acidity & 2 & 4.5 \\
Vaginal bleeding & -- & -- \\
Lower abdominal pain & 5 & 11.1 \\
Irregular movement of the fetus & 4 & 8.9 \\
Soiling of hands, legs, and face & & \\
\hline Knowledge on/of supplement medicines (iron, zinc, folic & & 46.6 \\
acid, etc.) during pregnancy & 21 & 53.4 \\
Yes & 24 & \\
No & & \\
\hline
\end{tabular}

Source: Field study, 2019. 
Table 2 declares the respondent's knowledge of antenatal care (ANC) during pregnancy. Among the total 45 respondents, 25 have a sound knowledge on the frequency of minimum visits of ANC, and 20 respondents didn't know of ANC visits. Similarly, out of 45 respondents, 14 had sound knowledge of WHO guidelines for ANC for pregnancy checking, and 31 were unknown about ANC checking. Among the 45 respondents, 34 had knowledge of vomiting, headache, and acidity caused by pregnancy, 2 respondents known about bleeding during the period. All the 45 respondents did not know about lower abdominal pain during the pregnancy, and 5 respondents knew about the irregular movement of the fetus. In response to knowledge on supplement medicines during pregnancy, 24 respondents were unknown, and 21 respondentsknewand 4 respondents had the experience of the swelling of hands, legs, and face during the pregnancy period.

\section{Age and Pregnancy}

Age isdirectly related to the biological factor for pregnancy. It is an essentialfactor, which plays a vital role in the issues of safe motherhood. Delaying marriage often delays first birth, and can also reduce the total number of children. Pregnancy atearly age causes mother's health to be pathetic, and further, it could lead to a high child mortality rate. Furthermore, high child mortality reduces the birth spaces as the mother is obliged to conceive again. With lower birth spaces, mother's health deteriorate. Similarly, pregnancy at later age is also not considered to be good for the mother and the child's health as well. Therefore the mother should know the proper age for pregnancy.All of the respondents know how the age factor plays a significant role in the pregnancy.

The respondents said that the age factor is significant for pregnancy. Age at the first pregnancy affects the Health of the mother, and the newborn baby. In many communities, girls are married at an early age. Since they are in adolescence, they often lack information about reproductive Health and sexuality, and also have little access to family planning and reproductive health services. Female health status is associated with marriage, and motherhoodin many developing countries, and even the youngest bride faces the pressure to prove that they are fertile. In sucha case, when a woman conceives at an early age, she might have to face various complications of pregnancy, and hence pregnancy at very young age may lead to the death of both mother and infant. Table 3: Knowledge of suitable age for pregnancy

\begin{tabular}{|l|l|l|}
\hline Age for pregnancy & No.of respondents & Percentage \\
\hline Below18 years & 8 & 17.8 \\
Above18 years & 37 & 82.2 \\
\hline Total & 45 & 100.0 \\
\hline
\end{tabular}

Source: Field survey, 2019. 
The table 3 shows that 8 respondents who were below 18 years, didnot know the appropriate age for pregnancy, and 37 repondents who were above 18 years knew about the appropriate age for pregnancy. This data show the respondents knowledge about the suitable age for pregnancy.

\section{Work during Pregnancy}

It is well known that pregnant women should not involve in heavy physical work that might harm her and the fetus. The women should do light work and take rest as far as possible. The women are to do the job as they are the wage earners, and one day leave may leave them starving.

Table 4: work during pregnancy

\begin{tabular}{|l|l|l|}
\hline Types of work & No. of respondents & Percentage \\
\hline light work & 12 & 26.6 \\
regularwork & 30 & 66.7 \\
no work & 3 & 6.7 \\
\hline Total & 45 & 100.0 \\
\hline
\end{tabular}

Source: Field survey, 2019.

Table 4 shows that 12 (26.6\%) respondents do light work, likewise $30(66.7 \%)$ respondents do everyday work, and 3 respondents do not work. And it was found that most of the respondents $(66.7 \%)$ had done regularjob during pregnancy.According to the respondents regular works are those done by women in everyday life for their livelihood. These works include household activities, outhouse work, agricultural activities, firewood and fodder collection, water fetching from the river, and so on. Usually these works are done by the non-pregnant woman in everyday life. Likewise, light work means simple works like- cooking food, cleaning the utensils, and simple household chores which doesnt affect the pregnant woman's physical health.

\section{Food Consumption during pregnancy}

A mother's nutritional status is essentialfor the intrauterinedevelopment, and for protection against maternal mortality and morbidity. Thus during pregnancy, women should take nutritious food i.e.those foods enriched with vitamins, protein, and minerals. Nutritious food nourishes the mother as well as the baby.According to 79 years old Tharu woman, Maiti Chaudhari of the study area, there is a unique practice of fooding among the Tharu people for pregnant woman. According to theircustomary practice, the 
pregnant lady is given two portion of special nutritious food like meat, one share for her and another for the fetus.

Table 5: food consuming pattern of the mother during pregnancy

\begin{tabular}{|l|l|l|}
\hline Types of food & No. of respondents & Percentage \\
\hline $\begin{array}{l}\text { Same as usual food } \\
\begin{array}{l}\text { More than expected and more } \\
\text { nutritious food }\end{array}\end{array}$ & 34 & 75.5 \\
\hline Total & 45 & 24.5 \\
\hline
\end{tabular}

Source: Field study, 2019.

Regarding the food consumption pattern during pregnancy, table 5 shows that the majority of the respondents i.e. 34 respondents replied that pregnant women should intake the same as usual food. Similarly, 11 respondents replied that pregnant women should intake more than regularfood. Proper diet intake is essential for safe motherhood practices. Eatinghealthy and nutritious food during pregnancy means having ahealthy fetus and ahealthy mother. However, diet consumption depends on the income level and economic condition of the respective family. Those pregnant women can only consume a proper diet if they have knowledge and are able to afford it.

\section{Knowledge and Diphtheria and Tetanus (DT) immunization}

Diphtheria and Tetanus immunization of pregnant women is considered an essential maternal issue in developing countries, recognizing the fact that neonatal diphtheria and tetanus is one of the leading causes of neonatal deaths in developing countries. Pregnant women and the newborn baby should be protected against the diptheria and tetanus by providing DT injection. Pregnant women should receive two doses of DT to prevent herself and the unborn child. For full protection, a pregnant woman should receive at least two doses of DT during her first pregnancy administered one month apart and a booster shot during each subsequent pregnancy.

Knowledge of DT injection helps the mother to prevent herself and her baby from getting diptheria and tetanus. One such risk is the chance of being infected with tetanus during pregnancy. The infection can be transmitted to the fetus and can be lifethreatening for both mother and baby. Therefore, it is important to understand about tetanus and its vaccinations in pregnancy. All the $45(100 \%)$ respondents of this study received DT immunization during the pregnancy, according to WHOguidelines. All respondents knewabout DT injection. 


\section{The Practice of Safe Maternal health care}

Maximum respondents exposed that most of the deliveries take place in the hospital; it was because of increasing acceptance of institutional deliveries. Theplace is an important physical factor for delivery of women. Level of understanding about maternal Health, availability of services, and socio-economic condition of the family, determine the choice of place for delivery, i.e., home or hospital, which is presented in thegiven table.

Table 6: Delivery practices and postnatal care

\begin{tabular}{|l|l|l|}
\hline Place of Delivery & Number & Percentage \\
\hline Home & 9 & 20.0 \\
Government hospital/ Health Post & 35 & 77.8 \\
Private Hospital & 1 & 2.2 \\
Use of thedelivery kit & & \\
Yes & 2 & 22.2 \\
No & 7 & 77.8 \\
\hline Total & 45 & 100 \\
\hline
\end{tabular}

Source: Field study, 2019.

The data of table 6 shows that the maximum no. of women practice their delivery in government hospitalsi.e., 35 women were having their delivery in thegovernment hospitals. Similarly, 9 women delivered at home, which is followed by 1 women who had delivery at aprivate hospital.The use of safe delivery kits during the delivery is very essentialas, which prevents the mother and the baby from getting any kind of infection. Besides, using asafe delivery kit, is a part of safe motherhood practices. Likewise, thehome delivery kit was used by nine respondents 2 , and 7 respondents had not used the safe delivery kit in the case of home delivery which, indicates the lack of health knowledge on proper maternal health care.

\section{Postnatal Care Practices}

The World Health Organization (WHO) recently updated global guidelines on postnatal care for mothers and newborns through a technical consultation process. The new guidelines address the timing and content of postnatal care for mothers and newborns with a particular focus on resource-limited settings in low and middle income countries (WHO, 2013). They complement other recommendations on maternal, 
prenatal, and newborn Health as well as those recommendations on which type of health care worker can safely deliver key maternal and newborn health care interventions, which went through a similar guidelines development process (WHO, 2012). The postnatal and childbirth period is a critical phase in the lives of mothers and newborn babies. Themother should be informed about taking rest after delivery as it helps her to recover soon. Most of the respondents of the study area had an idea and knowledge onpostnatal rest. But they did not get the opportunity of postnatal rest after delivery. Economic condition, socio-cultural and ethnic practices play the vital role on postnatal care of the mother and baby. The mother's response is presented in thebelow table.

Table 7:The Practice of postnatal care

\begin{tabular}{|l|l|l|}
\hline Practice of postnatal rest & Number & Percentage \\
\hline Yes & 39 & 86.7 \\
No & 6 & 13.3 \\
\hline Total & 45 & 100 \\
\hline
\end{tabular}

Source: Field Survey, 2019.

Table 6 states that themajority of the respondents (39) knew about the postnatal rest, and 6 were unknown about postnatal care which indicates the poor practice of postnatal care.

\section{Conclusion}

Women play an important role in reproductive and productive responsibility. Nature has gifted women a capacity to bear a child. This childbearing is ultimately a biological process and depends on women's physical state. But some women lose life in the process of giving birth to a new living being. Women deserve the best possible health care through a happy and healthy pregnancy and childbirth. Age, occupation, income, and education are some of the factors that influence the practices of safe motherhood. Maternal Health is determined by various factors like health condition, nutritional status workload, family structure, pregnancy, economic status, hygiene, and sanitation, etc. It is well known that pregnant women should not involve in heavy physical work that might harm her and the fetus. The women should do light work and take rest as far as possible. During pregnancy, women should take nutritious food i.e.those foods enriched with vitamins, protein,and minerals. Eatinghealthy and nutritious food during pregnancy means having ahealthy fetus and ahealthy mother. However, diet consumption depends on the income level and economic condition of the 
respective family. Pregnant women should receive two doses of DT to prevent herself and the unborn child. The use of safe delivery kits during the delivery is very .essentialas, which prevents the mother and the baby from getting any kind of infection The postnatal and childbirth period is a critical phase in the lives of mothers and newborn babies.

\section{References}

Department of Health Service (DOHS). (2011). Annual report: F/Y 2010/11. Management Division, Department of Health Service, Teku, Kathmandu, Nepal. Retrieved from http://www.dohs.gov.np.

Ghai, O.P, Gupta P, \&Paul, V. K. (2005). Essential Pediatrics. $6^{\text {th }}$ Ed. New Delhi, Bangalore, India: CBS Publishers and Distributors.

Gyawali K, Paneru DP, Jnawali B, \& Jnawali K. (2013). Knowledge and practices on maternal health care among mothers: A Cross-sectional study from rural areas of mid-western development region Nepal. Journal of the Scientific Society; 40:913.

Levitt, Martha, and Kussel Nancy. (1998). The Magazine of the World Health Organization.

Lowe, M, Duan-Rung C., \& Song-lih H. (2016). Social and cultural factors affecting maternal health in rural Gambia: An exploratory. PLoS ONE, 11(9).

Ministry of Health- MoH/Nepal, New ERA/Nepal, and ICF. (2017). Nepal Demographic and Health Survey 2016. Kathmandu, Nepal.

Ministry of Health, Nepal; New ERA; and ICF (2016). Nepal Demographic and Health Survey Key Findings. Kathmandu, Nepal.

Oshima, K., \&M. Bhattarai. (2017). https://blogs.worldbank.org/endpovertyinsouthasia /engaging-communities-golden-1000-days-Nepal

Renkert S, Nutbeam D. (2001). Opportunities to improve maternal health literacy through antenatal education: an exploratory study. Health Promotion International. 2001, 16: 381-8. 10.1093/heapro/16.4.381.

Shrestha, B. (2004). 'Family Planning: The key to reduce Maternal Mortality'. Population Magazine. Kathmandu: CDPS.

WHO. (2019). Trends in maternal mortality: 2000 to 2017: estimates by WHO, UNICEF, UNFPA, World Bank Group and the United Nations Population Division. Geneva: World Health Organization; 2019.

WHO. (2015). Strategies towards ending preventable maternal mortality (EPMM).Geneva: World Health Organization.

WHO. (2013). Recommendations on Postnatal Care of the Mother and Newborn. Geneva: World Health Organization. 
WHO. (2013). Recommendations on Maternal and Perinatal Health. Geneva: WHO. Guidelines on maternal, newborn, child and adolescent health approved by the WHO guidelines review committee.

WHO. (2012). Recommends optimizing health worker roles to improve access to key maternal and newborn health interventions through task shifting (WHO, 2012).

WHO. (2007). Maternal mortality in 2005: Estimates developed by WHO, UNICEF, UNFPA, and the World Bank. World Health Organization, Switzerland, p. 1-48.

WHO. (2006). Working together for Health. Geneva, Switzerland: World Health Report; 2006.

World Health Organization and United Nations Children's Fund. (2019). WHO/UNICEF joint database on SDG 3.1.2 Skilled Attendance at Birth. Available at: https://unstats.un.org/sdgs/indicators/database/

WHO. (2005). World Health Report 2005-make every mother and child count. World Health Organization, Switzerland.

https://www.mohp.gov.np/eng/program/reproductive-maternal-health/safe-motherhoodprogramme

http://www.nnfsp.gov.np/Ministry of Federal Affairs and Local Development Local Body Support Section 